\title{
Isolation and Characterization of Midgut Symbiotic Bacteria from Tsetse Flies (G.Pallidipes) and Their Role in Biological Control Methods
}

\author{
Firew Lejebo*, Abebe Girma \\ School of Graduate studies, Department of Biotechnology, Arba Minch University, Arba Minch, Ethiopia. \\ *Corresponding Author: Firew Lejebo, School of Graduate studies, Department of Biotechnology, Arba \\ Minch University, Arba Minch, Ethiopia.
}

\begin{abstract}
In this study isolation and Characterizations of Mid gut symbiotic bacteria from tsetse flies (Glossina pallidipes) and vector competence were undertaken. 50 flies were collected from Nech SAR National Park and brought to Arba Minch University, Laboratory of genetics and molecular biology. The tsetse flies were sterilized and dissected to isolate the symbiotic bacteria from the midgut. Various morphological and biochemical studies were conducted for characterization of the dominant isolate. Among the culture 13 isolates were found Gram negative, rod shaped, non motile and Catalase negative. The probable isolate found to be Sodalis sp. under the family Enterobacteriacae. The antibiotic sensitivity against these bacteria was performed and chloroamphenicol found to be potent to limit the growth of the isolate. The effect of chloroamphenicol on Tsetse flies were further checked and observed that it has no effect on the fertility of the tsetse but has indirect effect on the reproduction capability of the vector. Here we can conclude that chloroamphenicol could be taken as indirect alternative biological control strategy in tsetse flies.
\end{abstract}

Keywords: Antibiotics, Chloroamphenicol, Glossina, sodalis, Symbiont, Tsetse

\section{INTRODUCTION}

Livestock is an integral part of agricultural System in Ethiopia. According to CSA (2013), $82.4 \%$ of total population engaged in agriculture, of which, the country stands $1^{\text {st }}$ in Africa and $10^{\text {th }}$ in the world in livestock population. The Domestic animal population of the country is estimated to be 53.99 million cattle, 25.5 million sheep, 24.06 million goat, 0.92 million camel, 50.38 million poultry, 1.91 million horses, 0.35 million mules and 6.75 million donkeys (CSA, 2013). The full utilization of the product from such a huge number of livestock population particularly cattle's have been hampered due to tsetse transmitted trypanosomiasis (Southern Tsetse Eradication Manual, 2010).

The total area infested by tsetse flies is estimated to be $240,000 \mathrm{~km}^{2}$ in Southern, South western, Western, and North western part of the Ethiopia. Five species of tsetse flies, such as Glossina pallidipes, Glossina fuscipes, Glossina longipennis, Glossina tachnoides and Glossina morsistans exists commonly in the aforementioned areas. Both sexes of tsetse flies are haematogenous where transmission of trypanosomiasis occurs commonly (Southern Tsetse Eradication Manual, 2010). Therefore, Tsetse transmitted animal trypanosomiasis is a potential treat to livestock agricultural development and productivity in the country.

The trypanosome parasites could be injected when an infective tsetse pierces the skin to take a blood meal from the host. In such a case, trypanosomiasis have become mainly a serious constraint to livestock production in areas of the South west of Ethiopia at altitudes lesser than $1700 \mathrm{~m}$ above sea level (Langridge, 1976).Tsetse flies (Diptera: Glossinidae), which feed exclusively on vertebrate blood, harbour three distinct species of endosymbiotic bacteria that presumably play different roles in the flies. These bacteria include Wigglesworthia glossinidia, genus Sodalis, and genus Wolbachia. These symbioses are successful in large part because the above-mentioned bacteria have adapted to the tsetse flies unique viviparous reproductive physiology. Studies have been carried out on tsetse gut microbiota and the contribution of microbial symbionts to the host's nutritional homeostasis (Dillon and Dillon, 2004). Little attention has been given to the economic impact of the tsetse and the symbiont in vector competence in Gamo Gofa, Southern Nations, Nationalities and Peoples Regional State (SNNPRS). For example Arba Minch has about 68,323 cattle population (ATAO, 2013). 


\subsection{Statements of the Problem}

Trypanosome transmission resulted from the multifactors interaction between several organisms, including the pathogen, the vector, wild reservoirs, and the human host. While this interdependence can be complicated, it provides numerous opportunities for interfering with the transmission of the disease ( Akman etal, 2001). However, current solutions involve treating infected hosts with synthetic chemicals and/or inhibiting further transmission by attempting to reduce the insect vector population with insecticides remain in effective (Akman etal, 2001, Docampo and Moreno. 2003; Donelson, 2003).The vector because of the midgut micro-flora ensure vector competence, unless alternative method is designed to control the development of symbionts inside, the vector might cause a serious problem in livestock productivity particularly in Ethiopia. The main problems associated with them are mortality, abortion, decreased in milk and meat production, weakening of draft and ploughing animal (STEP Manual, 2010).

\subsection{Significance of the Study}

Now a day in Ethiopia the widely used control method of tsetse fly is the use of Sterile Insect Techniques (SIT) and insecticide without the clear understanding of the role of endosymbiotic bacteria. Among the three endosymbiotic bacteria only Glosinidus sodalis is culturable in the laboratory (Dale and Maudlin, 1999). This bacterium has the role in facilitating penetration of the midgut membrane and hence entry of the parasite in to the mid gut for maturation and growth. Controlling of this process will have significant impact in vector competence and hence control of vector and the damage due to tsetse transmitted trypanosomiasis. The study of such symbiotic bacteria for tsetse fly vector competence is little or incomplete.

The various species of the tsetse flies and their midgut micro-symbiotic bacteria have not been assessed as such. Hence, the present study will give a focus on characterization of midgut symbiotic bacteria from tsetse flies, its role in vector competence, and to use it as baseline information for biological control methods.

\section{OBJECTIVES}

\subsection{General Objective}

- To isolate symbiotic bacteria from the mid gut of Glossina pallidipes in the laboratory and evaluate its role in biological control methods.

\subsection{Specific Objective}

- To isolate symbiotic bacteria from mid guts of tsetse flies.

- To characterize bacterial flora based on biochemical and morphological test.

- To evaluate the role of the bacteria in vector competence

- To identify appropriate antibiotic against symbiotic bacteria to be used for biological control method.

- To cultivate the isolated bacteria

- To determine their sensitivity to antibiotics administered through the blood meal of the fly

\section{Materials AND Methods}

\subsection{Description of Study Area and Sample Collection}

Fifty flies of Glossina pallidipes were randomly collected from Nech SAR National Park, Arba Minch. Arba Minch is one of the fifteen woredas and two administrative town of Gamo Gofa zones. It is located at $505 \mathrm{~km}$ South of Addis Ababa in Gamo Gofa Zone, Southern Nations, Nationalities and Peoples Regional State (SNNPRS). It is situated in Great African Rift Valley at an elevation of about 1285 meters above sea level according to the Arba Minch town administration office report (ATAO, 2013). 


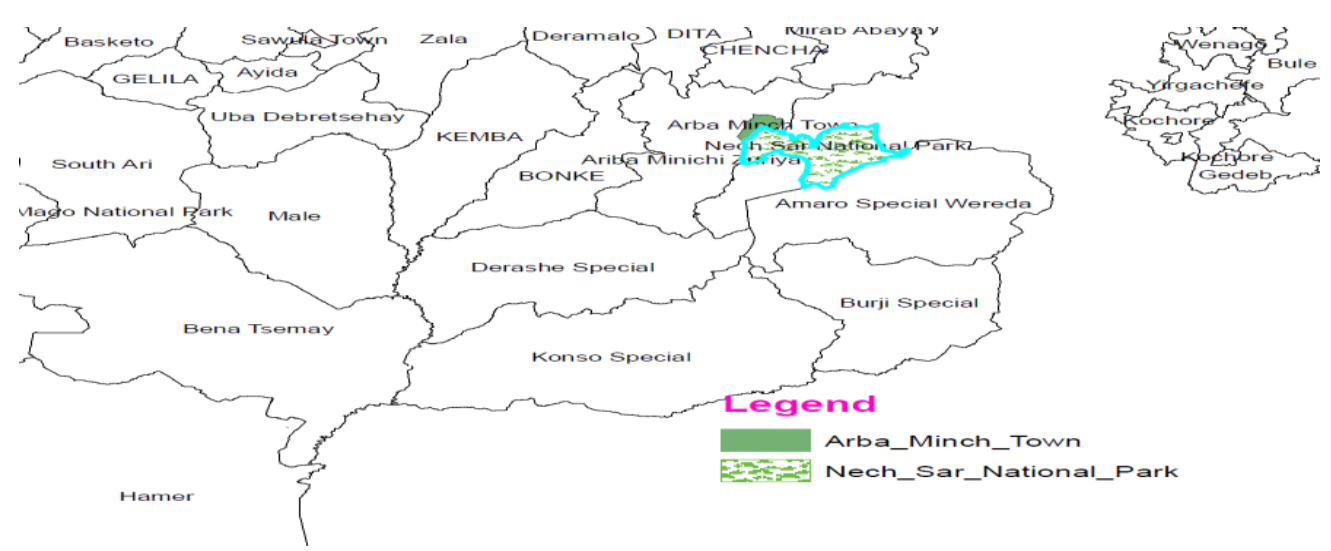

Figure3. Map of the study area

\subsection{Study Methodology}

\subsubsection{Materials}

The lists of equipment and chemicals used includes trap, phenol, acetone, cow urine, adult tsetse fly, pin, rubber and grease, fly dissection kit, test tubes, auto clave, vortex shaker, magnetic stirrer, ph meter, incubator, weighing balance, flasks, laminar air flow cabinet, eppendroffs tubes, Ethanol, phosphate-buffered saline (pbs), inoculating loop, petridish, microscopic slide, oil immersion, refrigerator, stereo microscope, hot plate, sodium hypochlorite, distilled water, Bunsen burner, glass rod, feeding cage and membrane for feeding.

\subsubsection{Methods}

- Tsetse Capture and Identification

Tsetse flies were identified by using a modified entomological key (Buxton, 1955). The tsetse fly species Glossina pallidipes was randomly collected from Nech Sar National Park, Arba Minch. Then the adult tsetse flies were taken to the laboratory, Arba Minch University for dissection and further experiments.

The method for collection of the flies is shown in figure 4.

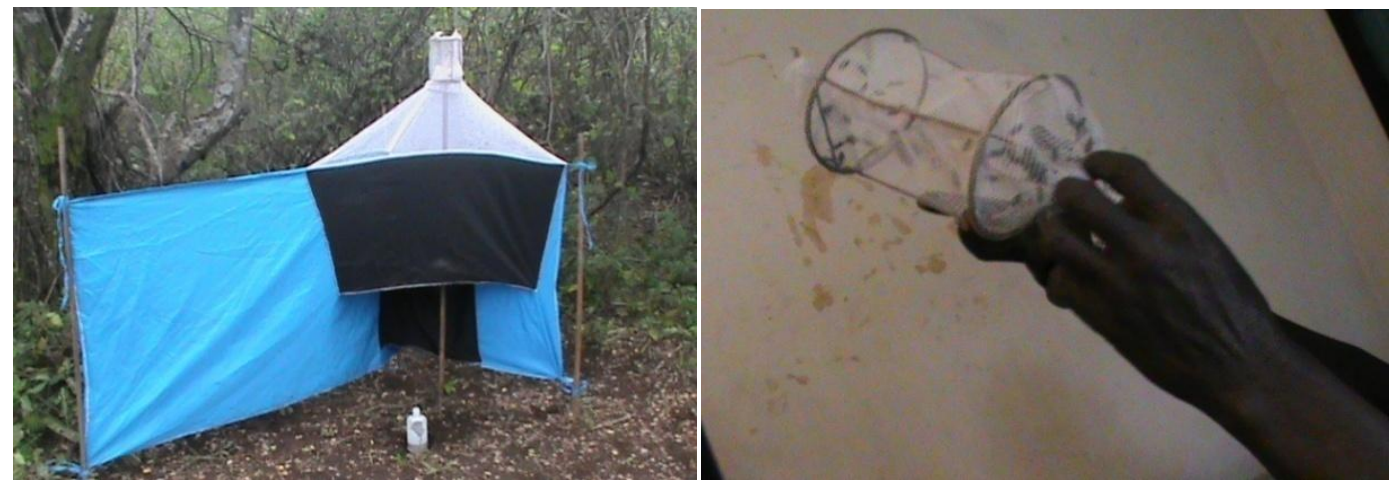

Figure4. Collection of flies from the Nech SAR National park by using NGU trap

- Dissection of Tsetse

A newly collected adult flies were selected and dissected for midgut micro-biota isolation and identifications. Dissections were made under sterile condition (FAO, 1982). For this individual insect was then surface sterilized with a $70 \%$ ethanol solution and rinsed three times in sterile phosphatebuffered saline (PBS). Midgut of each insect was then carefully removed using clean forceps and homogenised in $100 \mu$ l of sterile PBS using eppendroff tubes and was kept in $-4^{\circ} \mathrm{C}$ freeze. The whole procedure was performed using stereo microscope ( $10 \times$ magnification).

- Culture Media Preparation and Isolation of Midgut Symbiotic Bacteria

The Mitsuhashi and Maramorosch insect (MMI) media was prepared by using the chemicals mentioned below in Table 1. 
Isolation and Characterization of Midgut Symbiotic Bacteria from Tsetse Flies (G.Pallidipes) and Their Role in Biological Control Methods

Table1. Chemical composition of MMI insect culture media

\begin{tabular}{|c|c|}
\hline Ingredients & Grams/Liter \\
\hline Calcium chloride dihydarate & 0.19 \\
\hline Magnesium chloride anhydrouse & 0.046 \\
\hline Potassium chloride & 0.2 \\
\hline Sodium chloride & 7 \\
\hline Sodium phosphate monobasic & 0.173 \\
\hline D(+)glucose & 4 \\
\hline Casein hydrolysate & 6.5 \\
\hline Yeast extract & 5 \\
\hline agar & 15 \\
\hline
\end{tabular}

The midgut homogenate was cultured for isolation of symbionts. The Mitsuhashi and Maramorosch insect (MMI) culture medium was used in this study using the streak plate method and a pure isolated bacterial colony was obtained (Dale and Maudlin, 1999). All cultures were maintained at $37^{\circ} \mathrm{C}$ under aerobic conditions for 24 hours. Distinct colonies were taken for further purification of isolates. Individual bacterial colonies were re-streaked then a single pure colony was isolated. Colonies with distinct morphologies, colours and margins were picked and sub-cultured to obtain pure bacterial isolates. Pure colonies harvested were stored at $-4^{\circ} \mathrm{C}$.

\section{- Screening of Symbiont Isolate}

Screening and characterization of bacterial isolates were evaluated based on morphological and biochemical property of the isolates. Here various biochemical (citrate utilization, methyl red, vogesProskauer test, indole test, starch hydrolysis, casein hydrolysis test and catalase) and morphological (Gram staining, Motility, colony Shape, Size and color tests) were implemented. Then, the identification was made according to Berg's manual of determinative bacteriology (appendixI). All procedures for the biochemical test were shown on appendix $\mathrm{V}$ and VI

- Antibiotic Susceptibility Test

Using aseptic technique a sterile swab from a broth culture was taken by gently pressing and/or rotating the swab against the inside of the tube, using the swab Muller-Hinton agar was streaked and then the plate was allowed to dry for five minutes. Using a flame sterilized forceps a disc was pressed gently to allow disc containing a specific antibiotic to the plate and finally the plate was incubated over night at a temperature of $37^{\circ} \mathrm{c}$ (Mohantly, 2010).

The antibiotics used for the sensitivity tests in different plates were streptomycin $(10 \mu \mathrm{g})$, tetracycline (30 $\mu \mathrm{g})$, and penicillin $\mathrm{g}(10 \mu \mathrm{g})$, ampicillin $(10 \mu \mathrm{g})$, chloroamphenicol $(10 \mu \mathrm{g})$, gentamycin $(10 \mu \mathrm{g})$, erythromycin $(15 \mu \mathrm{g})$ and cloxacilin $(30 \mu \mathrm{g})$ (manufacture's recommendation). With this method, zone of inhibitions were measured for each of the antibiotics using a ruler, and then high zone of inhibition was taken for further study (Mohantly, 2010).

- Insect Feeding and Effect of Antibiotic

According to the standard guide line manual of FAO/IAEA(FAO, 1982), a Gamma cell sterilized blood which was collected from abattoir was given to the 140 tsetse flies treated with antibiotic for 70 and untreated for the other 70 flies on the feeding membrane as shown in figure 6 .

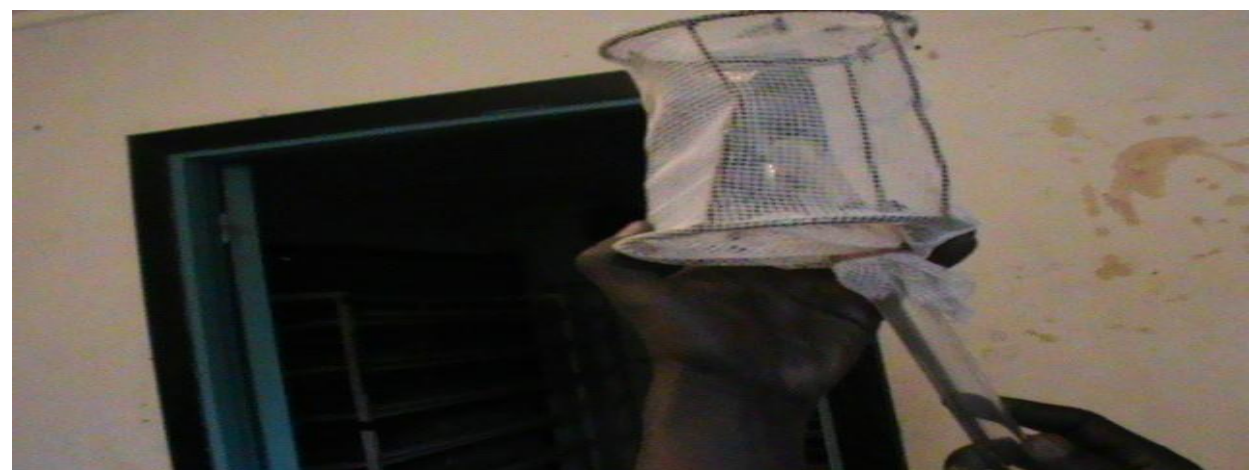

Figure5. Placing of field collected flies into a feeding cage 


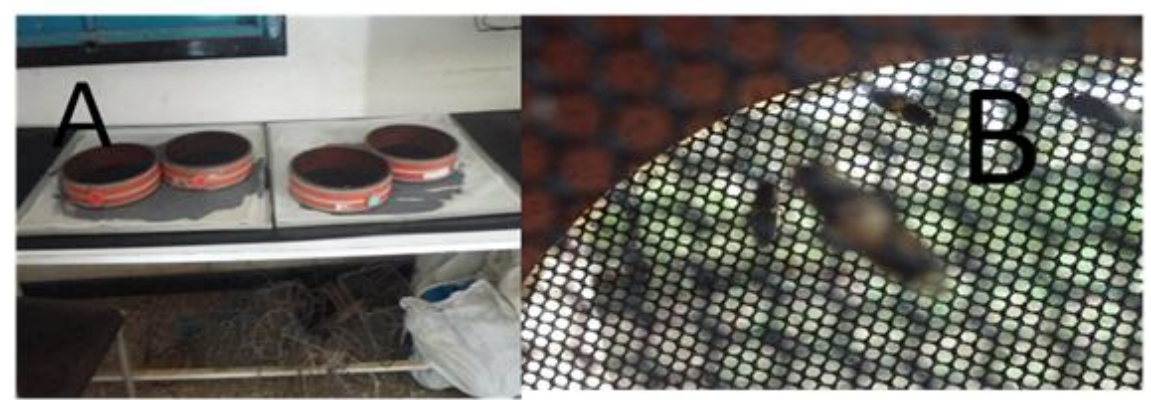

Figure6. Feeding of flies (A/Membrane feeding offlies B/ Fed flies)

For this study the blood was mixed with antibiotic (Chloramphenicol $30 \mu \mathrm{g} / \mathrm{ml}$, cloxacillin $30 \mu \mathrm{g} / \mathrm{ml}$ and Gentamycin $10 \mu \mathrm{g} / \mathrm{ml}$ ) and the control was prepared without the antibiotics. The effect of antibiotic on the growth of symbiotic bacteria which has role in transmission of trypanosomiasis and hence helps in vector competence was monitored for 21 days. Then after, the flies were also dissected to check the presence of the symbiotic bacteria, fecundity and longevity. Accordingly, the death of isolate, fecundity and longevity of flies in both experimental and control groups were counted and compared in order to see the effect of antibiotic.

- Study Design and Data Analysis

Cross-sectional type of study was used in this study. The entire data source was recorded in Excel spread sheets and then it was displayed using tables and graphs. All the experiments were conducted in duplicates.

\section{Results}

\subsection{Isolation and Characterization of Symbionts}

The 50 adult tsetse flies from various corners of Nech SAR national park were collected for this study. Randomly selected tsetse flies were sterized and dissected for isolation and characterization of symbiotic bacteria harboring in the midgut of the insect. Around 100 colonies were isolated in stepwise isolation procedures; of which 16 isolate were motile and the 84 are non-motile. Then 100 colonies were further characterized based on their morphological and biochemical properties. The result is shown in table 2 and figure 8.
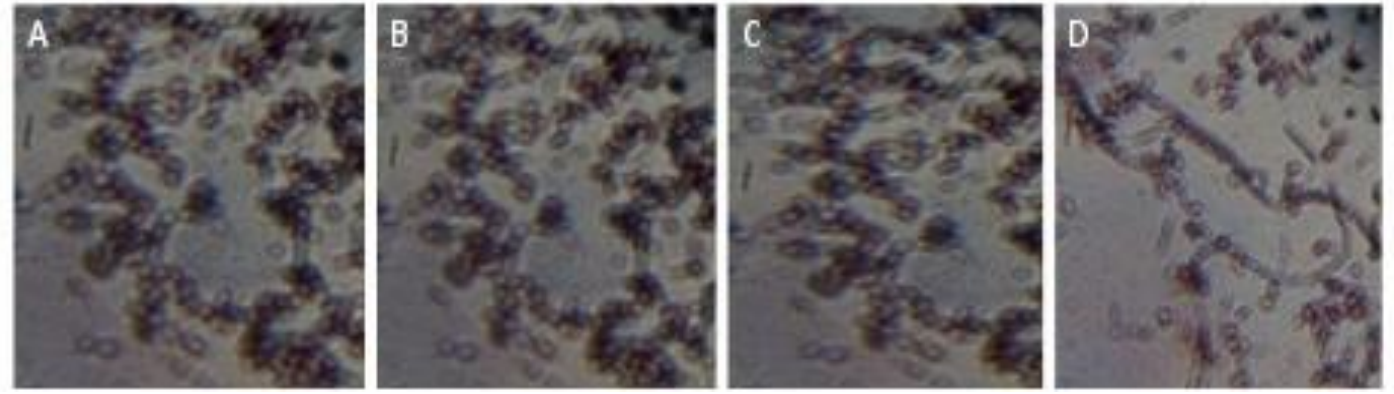

Figure7. Gram stained morphology of bacteria A) Gram negative cocci rod B) gram negative cocci and rod C) Gram negative cocci D) Gram negative yellow

The morphological features of the isolates such as Gram-negative, non-motile, rod-shaped nature were similar to enterobacteriacae family based on Bergey's manual of determinative bacteriology (appendix I). The result confirmed that the probable isolate dominantly dwell in tsetse flies midgut was Sodalis sp. (table 2).Then the aforementioned isolates further examined for their biochemical properties.

Table2. Morphological characteristics of the bacteria

\begin{tabular}{|c|c|c|c|c|c|}
\hline \multirow{2}{*}{$\begin{array}{c}\text { No of } \\
\text { Isolates }\end{array}$} & \multicolumn{4}{|c|}{ e Morphological characterization } \\
\cline { 2 - 5 } & \multicolumn{2}{|c|}{ Microscopic characteristics } & \multicolumn{3}{c|}{ Colony characteristics } \\
\cline { 2 - 5 } & Gram staining & Motility & Shape & Size & color \\
\hline 16 & G -ve & motile & Rod & small & Yellowish \\
\hline 18 & G + ve & Non motile & Rod & small & Yellowish \\
\hline
\end{tabular}


Isolation and Characterization of Midgut Symbiotic Bacteria from Tsetse Flies (G.Pallidipes) and Their Role in Biological Control Methods

\begin{tabular}{|c|c|c|c|c|c|}
\hline 30 & G +ve & Non motile & Circular & small & Yellowish \\
\hline 28 & G -ve & Non motile & Rod & small & Yellowish \\
\hline 8 & G +ve & Non motile & circular & small & Yellowish \\
\hline
\end{tabular}

The result of the biochemical tests is shown below in table 3 and figure 8 . It was further confirmed that common isolate harboring in the midgut of the tsetse flies is Sodalis sp.

Table3. Biochemical characterization of bacteria

\begin{tabular}{|c|c|c|c|c|c|c|c|}
\hline \multirow[t]{2}{*}{ Isolates } & \multicolumn{6}{|c|}{ Biochemical test characterization } & \multirow{2}{*}{$\begin{array}{r}\text { Casein } \\
\text { hydrolysis }\end{array}$} \\
\hline & Catalase & $\begin{array}{c}\text { Citrate } \\
\text { utilization }\end{array}$ & Methyl red & VP test & $\begin{array}{c}\text { Indole } \\
\text { Test }\end{array}$ & $\begin{array}{c}\text { Starch } \\
\text { hydrolysis }\end{array}$ & \\
\hline 22 & -ve & $+\mathrm{ve}$ & -ve & $+\mathrm{ve}$ & -ve & -ve & -ve \\
\hline 14 & -ve & +ve & -ve & -ve & $+\mathrm{ve}$ & -ve & -ve \\
\hline 36 & -ve & $+\mathrm{ve}$ & $+\mathrm{ve}$ & -ve & $+\mathrm{ve}$ & -ve & -ve \\
\hline 13 & -ve & $+\mathrm{ve}$ & $+\mathrm{ve}$ & -ve & $+\mathrm{ve}$ & -ve & -ve \\
\hline 15 & -ve & +ve & +ve & -ve & $+\mathrm{ve}$ & -ve & -ve \\
\hline
\end{tabular}
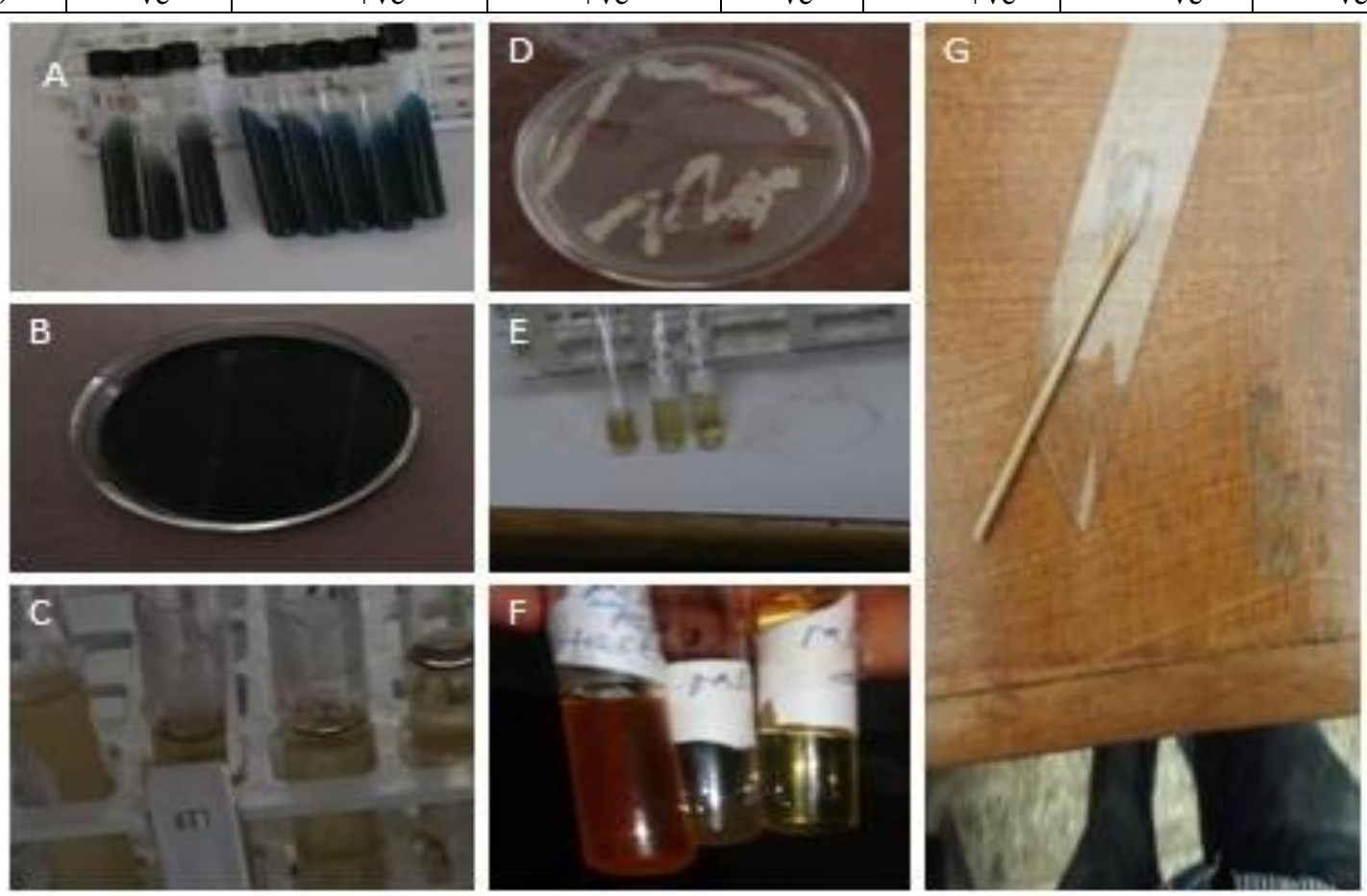

Figure8. biochemical tests: A ) Citrate utilization test B) Starch hydrolysis test C) Indole test D) casein hydrolysis test E) Vogus proskauer test F)Methyl red test G) Catalase test

\subsection{Effects of Antibiotics on the Isolate Sodalis Sp}

Antibiotic susceptibility tests were conducted using various antibiotics streptomycin $(10 \mu \mathrm{g})$, tetracycline $(30 \mu \mathrm{g})$, penicillin $\mathrm{g}(10 \mu \mathrm{g})$, ampicillin $(10 \mu \mathrm{g})$, chloroamphenicol $(10 \mu \mathrm{g})$, gentamycin $(10 \mu \mathrm{g})$, erythromycin $(15 \mu \mathrm{g})$ and cloxacilin $30 \mu \mathrm{g}$ in $\mu \mathrm{g} / \mathrm{ml}$ against Sodalis sp. The zone of clearance was recorded. The result showed that chloramphenicol is the best antibiotic so as to control growth of Sodalis sp. However, penicillin g and streptomycin were found to be ineffective (Table 4).

Table4. Antibiotic susceptibility of the isolates

\begin{tabular}{|c|c|c|cc|}
\hline Antibiotic & Unit & Zone of inhibition & Sensitivity isolate \\
\hline Penicillin G & $10 \mu \mathrm{g}$ & $19 \mathrm{~mm}$ & Sensitive & 2 \\
\hline Streptomycin & $10 \mu \mathrm{g}$ & $16 \mathrm{~mm}$ & Sensitive & 2 \\
\hline Erythromycin & $15 \mu \mathrm{g}$ & $31 \mathrm{~mm}$ & Highly sensitive 2 \\
\hline Gentamycin & $10 \mu \mathrm{g}$ & $28 \mathrm{~mm}$ & Highly sensitive 2 \\
\hline Cloxacilin & $30 \mu \mathrm{g}$ & $29 \mathrm{~mm}$ & Highly sensitive 2 \\
\hline Ampicillin & $10 \mu \mathrm{g}$ & $22 \mathrm{~mm}$ & Sensitive & 2 \\
\hline Chloramphenicol & $30 \mu \mathrm{g}$ & $32 \mathrm{~mm}$ & Highly sensitive 2 \\
\hline Tetracycline & $30 \mu \mathrm{g}$ & $25 \mathrm{~mm}$ & Sensitive \\
\hline
\end{tabular}




\subsection{Effects of Antibiotics on the Vector}

For this study 140 tsetse flies were collected and brought to Arba Minch University to evaluate the effect of antibiotics based on the order of manufacturers $(\mu \mathrm{g} / \mathrm{ml})($ Gentamycin $100 \mathrm{ml}$, Cloxacilin $500 \mathrm{mg}$ and Chloramphenicol 500mg) that showed maximum clearance of the Sodalis sp. growth. The study was conducted preparing the blood meal mixed with antibiotics and the controls were prepared without the antibiotic. All experiments were maintained in separate identical cages and incubated at $25{ }^{\circ} \mathrm{C}$ for 21 days. Then after, flies were removed, sterilized and dissected. The bacterium were isolated and transferred to culture media and maintained at $30^{\circ} \mathrm{C}$. Throughout the experiment the number of larvae laid (fecundity), longevity and number of flies dying were recorded.

Seventy flies were feed with blood meal treated with antibiotics Chloroampenicol 500mg of these 10 had died by the day 21 (five were removed for dissection and culturing) but Cloxacillin and Gentamycin treated 70 flies resulted in death. In addition, from the other seventy control flies 6 flies died and 5 flies were removed for dissection at the same day. Flies from both control and treated groups died, because of starvation, none of the control and treated group died with blood in the alimentary canal (Figure.9). Five control and four experimental flies produced larvae on the 10th day (figure.10). However, Gentamycin 100ml, Cloxacilin 500mg treated flies doesn't produced any larvae.

The study showed that chloroampenicol can be a potential antibiotic clear the Sodalis sp. and make the tsetse incompetent.

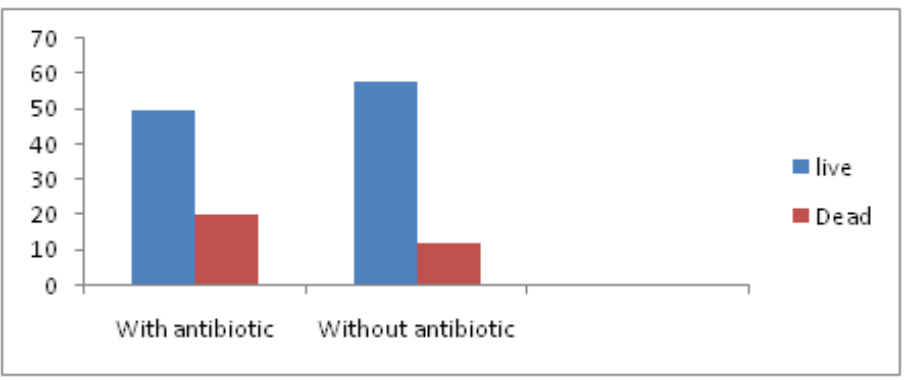

Figure9. Comparison of feeding of flies with and without antibiotic
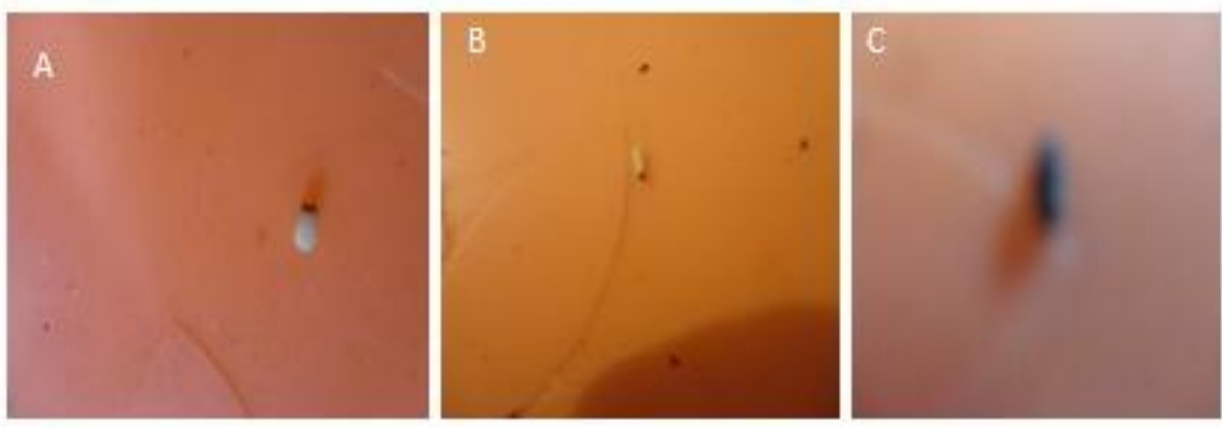

Figure10. Tsetse larvae development A) experimental B) control C) Pupae

The study further assessed the effect of the antibiotic on the Sodalis sp. isolated from experimental and controls tsetse flies midgut. The result showed that the experimental group of tsetse flies had no Sodalis sp. grown, however the control group had Sodalis sp as shown in figure.11.
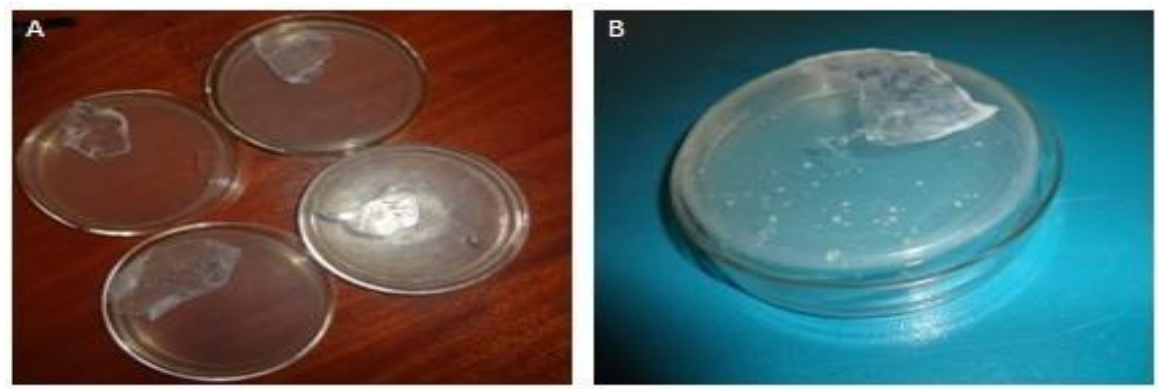

Figure11. Growth of Sodalis sp isolated A) Experimental B) Control 


\section{DISCUSSION}

Tsetse flies are the major problem both productivity and quality of livestock in Ethiopia. Various studies showed that the vector competence is the result of the symbiotic bacterial harboring particularly in the midgut. Unlike other insect symbionts such as the intracellular Wigglesworthia and Wolbachia bacteria, Sodalis bacteria commonly found in tsetse flies midgut. The functional role of Sodalis symbiosis in tsetse is unknown; however, some studies showed that its elimination by streptozotoicin is associated with decreased longevity in the progeny (Dale and Welburn, 2001). Other studies also confirmed that Sodalis is implicated in the host's ability to establish trypanosome infections (Welburn and Maudlin 1991; Welburn and Maudlin, 1999). Sodalis has been detected in the milk gland organ and thus may be transmitted to the progeny via the milk gland secretions and Vector competence (Dale and Maudlin, 1999; Dale and Welburn, 2001).

Hence our study focus on the search of symbiotic bacteria from midgut of tsetse flies collected from Nech SAR National park, Ethiopia. The isolation and characterization of the bacteria mentioned was undertaken by morphological and biochemical test using Bergey's manual of determinative bacteriology.

The study considers 50 tsetse flies collected from various corners of the park were subjected to sterilization and dissection in order to isolate the bacteria from the midgut. Around 100 distinct colonies were isolated in a stepwise procedure. Base on the morphological features 16 colonies were motile and the rest were non-motile (Table .2). In terms of colony shape around 62 were found to be rod shaped and the rest were nearly circular. The color of the entire colony was found to be yellow (Table.2). From the result showed that the isolates were showing characteristics similar to Enterobacteriacae family most likely 28 of the 100 colonies showed similarity to the genus Sodalis.

On the basis of biochemical features various tests were conducted of which 13 were catalases negative and the rest were positive. This negative catalase test particularly confirmed that the probable isolate is Sodalis sp as shown in table 3. Toh etal., 2006, showed the result similar to our findings .

The effects of antibiotics such as penicillin g, streptomycin, erythromycin, gentamycin, cloxacilin, ampicillin, chloramphenicol and tetracycline in recommended doses against Sodalis sp were evaluated. The result showed that Gentamycin, Cloxacilin and Chloramphenicol were the potent antibiotics that control the growth of Sodalis. Of which Chloramphenicol scored the highest zone of clearance in our study (Table 4). On the other hand, Penicillin G and Streptomycin were shown insignificant effect on the growth of the bacteria. Research also reported that penicillin antibiotics were not be able to affect the intracellular forms of the Sodalis symbionts (Beard, 1993). In their report, the penicillin antibiotics do not impair the transmission of Sodalis to progeny as well. Molecular biological study confirmed that the resident Sodalis population in the milk is apparently cleared; intracellular forms remain within the milk gland cells (Beard, 1993; Dale and Welburn, 2001).

The effect of the antibiotics particularly Chloramphenicol on the vector growth and development were further evaluated. For this study 140 new tsetse flies were collected and the experiments were carried out in two groups experimental and control. The experimental group includes 70 flies fed on blood meal treated with antibiotic. Around 10 flies were found dead within 21 days of incubation. From the experiment there is no significant difference between the control and the experimental groups. The cause for the death of the tsetse flies seems normal due to starvation and the change in environment (Figure 9). In addition some of the tsetse flies both from the experimental and control groups were able to lay larvae within 10 days of the incubation time. Hill etal., 1973 reported the treatment of tsetse flies with antibiotics affects the fertility of the females similar to our study.

These result showed us a direction to check the change in the dynamics of the microbiota populations. The insects both from the control and experimental groups were taken sterilized and dissected to assess the presence of microbes from the midgut.The results were observed to contain more growth of Sodalis on control and no growth of bacteria on the experimental groups (Figure 11).

According to the report by, Beard, (1993), the presence of intact Wigglesworthia and Sodalis in the bacteriome organ of antibiotic-treated females enables the maintenance of host fertility and results in a fecundity index comparable to that of control flies. The functional role of Sodalis symbiosis in tsetse has been reported to be associated with decreased longevity in the progeny (Dale and Welburn, 2001). 
Other studies also confirmed that Sodalis is implicated in the host's ability to establish trypanosome infections and proliferation (Welburn and Maudlin 1991; Welburn and Maudlin, 1999). All these findings confirmed that Sodalis is the vital principle for vector competence and Chloramphenicol can be taken as an alternative method to control the effect of tsetse on livestock population as a semi biological control.

Beard, (1993) reported that few Sodalis cells transmitted to intrauterine larvae can establish infections and proliferate to reach normal adult density levels of pupal development period. In addition he further explained that, multiple routes of transmission exist for Sodalis, including transovarial and paternal routes. Huebner and Davey (1974) also found bacteroids in the ovaries of G. austeni indicating that transmission from one generation to the next was transovarian.

\section{CONCLUSION AND RECOMMENDATION}

The total area infested by tsetse flies is estimated to be $240,000 \mathrm{~km}^{2}$ in Southern, South western, Western, and North western part of the Ethiopia. Five species of tsetse flies, such as Glossina pallidipes, Glossina fuscipes, Glossina longipennis, Glossina tachnoides and Glossina morsistans commonly exists in Ethiopia. The tsetse flies competence largely dependent on symbiotic microorganisms.

Here in this study the isolation and characterization of the symbiotic bacteria were considered. Different morphological and biochemical tests confirmed that the probable species was Sodalis $\mathrm{sp}$ which is the principal in vector competence. The effects of antibiotics on the isolate were carried out and chloramphenicol found to be potent to control the growth of Sodalis. In addition, the effect of Chloramphenicol on the vector was checked, and the growth and development remains normal. These confirmed that Chloramphenicol indirectly can be taken as an alternative biological control strategy to tsetse spread. Hence, based on our findings the following recommendation and future directions should be considered

* Wider geographic and ecological niches to study symbiotic bacteria from Tsetse fly

* Molecular and biotechnological studies on symbiotic bacteria.

* The relationship between insecticide/pesticide resistance and the presence of the symbiotic bacteria should priority areas.

* The difference in the harboring symbionts in other species of tsetse.

* The effect of vector competence other than symbionts

* The role of symbionts other than sodalis should be assessed.

\section{ACKNOWLEDGEMENT}

First of all I would like to praise lord.

Next I am highly grateful to Dr Abebe Girma, my advisor, for his friendly approach, steady guidance, valuable advice, close supervision, provision of relevant materials, and correction of this paper. I would also like to thank my co-advisor, Dr Thomas Cherenet, the Director General for National tsetse and trypanosomiasis eradication project, for his father hood guidance, encouragement, and creation of favorable environment for my study. My acknowledgement also extended to Arba Minch University, College of natural sciences, Department of Biology in the facilitation of all relevant materials during my study. Besides this, I also like to thank laboratory assistances, Mr Nigatu Elgo and Abebe Bashe, for their provision of all the relevant laboratory equipment and chemicals, and Mr. Fekadu Masebo for his valuable advice during the research. Finally, the acknowledgement would not be stopped without thanking my Wife; Geni and my Mami; Almi, and the stuff of STEP Arba Minch field Station particularly Aschenaki Kalsa and Netsanet Asfaw for their Continuous encouragement throughout my study.

\section{REFERENCES}

[1] Akman, L., R. V. Rio, C. B. Beard, S, Aksoy. 2001. Genome size determination and coding capacity of Sodalis glossinidius, an enteric symbiont of tsetse flies, as revealed by hybridization to Escherichia coli gene array. J. Bacteriol. 183:4517-4525.

[2] Akman, L., A. Yamashita, H. Watanabe, K. Oshima, T. Shiba, M. Hattori, S. Aksoy. 2002. Genome sequence of the endocellular obligates symbiont of tsetse, Wigglesworthia glossinidia. Nat. Genet. 32:402-407. 
[3] Aksoy, S. 2000. Tsetse-a haven for microorganisms. Parasitol. Today. 16: 114-118.

[4] Aksoy, S., W. C. Gibson, M. J. Lehane. 2003. Interactions between tsetse and trypanosomes with implications for the control of trypanosomiasis. Adv.Parasitol. 53:1-83.

[5] Alam, U., Medlock, J., Brelsfoard, C., Pais, R., Lohs, C., Balmand, S. 2011.Wolbachia symbiont infections induce strong cytoplasmic incompatibility in the tsetse fly Glossina morsitans. PLoS Pathog.7 (12): 1002415.

[6] Arba Minch town Administration office (ATAO). 2013. Report on Gamo Gofa Zone, Arba Minch town administration office.

[7] Attardo, G. M. C., Lohs, A., Heddi, U. H., Alam, S., Yildirim. S, Aksoy. 2008. Analysis of milk gland structure and function in Glossina morsitans: milk protein production, symbiont populations and fecundity. J.Insect Physiol. 54: 1236-1242.

[8] Azambuja, P., Feder, D., Garcia, E.S. 2004. Isolation of Serratia marcescens in the midgut of Rhodnius prolixus: impact on the establishment of the parasite. Trypanosoma cruzi in the vector. Exp.Parasitol. 107: 89-96.

[9] Barrett, K., Okali, C. 1998. Partnerships for tsetse control: community participation and other options. World. Anim. Rev. 6:39-46.

[10] Beard, C. B., S. L. O'Neill, P. Mason, L. Mandelco, C. R. Woese, R. B. Tesh, F. F. Richards, S. Aksoy. 1993. Genetic transformation and phylogeny of bacterial symbionts from tsetse. Insect Mol. Biol. 1:123131.

[11] Buxton, P. A. 1955. A natural history of tsetse flies: an account of the biology of the genus Glossina (Diptera). London School of Hyg. and trop. Med. Mem.10:80-82.

[12] Cheng, Q., Aksoy, S. 1999. Tissue tropism, transmission and expression of foreign genes in vivo in midgut symbionts of tsetse flies. Insect Mol. Biol. 8:125-132.

[13] Cheng, Q., T. D. Ruel, W. Zhou, S. K. Moloo, P. Majiwa, S. A. O’Neill, S. Aksoy.2000. Tissue distribution and prevalence of Wolbachia infections in tsetse flies, Glossina spp.Med.Vet.Entomol. 14:44-50.

[14] Central Statistical Agency. CSA. 2013. Agricultural sample survey Report on Livestock and livestock characteristics .2:9-20.

[15] Dale, C., S. C. Welburn. 2001. The endosymbionts of tsetse flies: manipulating host-parasite interactions. International J. Parasitol. 31:628-631.

[16] Dale C, Maudlin I. 1999. Sodalis gen. nov. and Sodalis glossinidius sp.nov, microaerophilic secondary endosymbiont of the tsetse flies Glossina morsitans morsitans. Int.J.Syst.Bacteriol.49:267-275.

[17] Dillon, R.J., Dillon, V. M. 2004. The gut bacteria of insects: non pathogenic interactions. Annu. Rev. Entomol. 49: 71-92.

[18] Docampo,R. Moreno, S.N. 2003.Current chemotherapy of human African trypanosomiasis. Parasitol. Res. 90:10-13.

[19] Donelson, J. E.2003. Antigenic variation and the African trypanosome genome. Acta Trop. 85:391-404.

[20] Evans, D. A., Ellis, D. S. 1983. Recent observations on the behavior of certain trypanosomes within their insect hosts. Advances in Parasitology. 22:1-42.

[21] Farikou, O., Njiokou, F., Mbida „JAM., Njitchouang, GR., Djeunga, HN., Asonganyi, T., Simarro PP., Cuny, G., Geiger, A. 2010. Tripartite interactions between tsetse flies, Sodalis glossinidius, and trypanosomes-An epidemiological approach in two historical human African trypanosomiasis foci in Cameroon. Infect Genet Evol. 6:115-121.

[22] Food and Agriculture Organization. FAO.1982. Training manual for tsetse control personnel.Volume1.Tsetse biology, systematic and distribution; techniques, Rome, Italy.

[23] Geiger, A.G., Cuny, R, Fruots. 2005. Two tsetse fly species, Glossina palpalis gambiensis and Glossina morsitans morsitans, carry genetically distinct populations of the secondary symbiont, Sodalis glossinidius. Appl. Environ. Microbiol.71:8941-8943.

[24] Geiger, A., Ravel, S., Mateille, T., Janelle, J., Patrel, D., Cuny, G. 2007. Vector competence of Glossina palpalis gambiensis for Trypanosoma brucei and genetic diversity of the symbiont Sodalis glossinidius. Mol. Biol. Evol. 24:102-109

[25] Gibson, W., Bailey, M. 2003. The development of Trypanosoma brucei within the tsetse fly midgut observed using green fluorescent trypanosomes. Kinetoplastid Biology and Disease, www.Kinetoplastids .com/content/2/1/1.

[26] Glaser, R.L., Meola, M.A. 2010. The native Wolbachia endosymbionts of Drosophila melanogaster and Culex quinque fasciatus increase host resistance to West Nile virus infection. PLoS One 5:e11977. 
[27] Gonzalez-Ceron, L., Santillan, F., Rodriguez, M.H., Mendez, D., Hernandez- Avila, J.E.2003. Bacteria in midguts of field collected Anopheles albimanus block. Plasmodium vivax sporogonic development. J. Med. Entomol. 40:371-374.

[28] Hao, Z., I. Kasumba, M. J. Lehane, W. C. Gibson, J. Kwon, S. Aksoy. 2001. Tsetse immune responses and trypanosome transmission: implications for the development of tsetse-based strategies to reduce trypanosomiasis. Proc. Natl. Acad. Sci. USA. 98:12648-12653.

[29] Hill, P., Saunders, D., Campbell, J. A. 1973. The production of symbiont free Glossina morsitans and an associated loss of female fertility. Trans. roy. Soc. trop. Med. Hyg. 67:727-728.

[30] Hoare, C.A. 1970. The mammalian trypanosomes of Africa. In: Mulligan, H.W. The African trypanosomiasis. George Allen and Unwin, London, pp.3-23.

[31] Hooper, LV. 2004. Bacterial contributions to mammalian gut development. Trends Microbiol 12:129-134.

[32] $\mathrm{Hu}, \mathrm{C} ., \mathrm{S}$. Aksoy. 2006. Innate immune responses regulate trypanosome parasite infection of the tsetse fly Glossina morsitans morsitans. Mol. Microbiol. 60:1194-1204.

[33] Huebner, E. Davey, K. G. 1974. Bacteroids in the ovaries of the tsetse fly. Nature, Lond. 249: $260-261$.

[34] Hu, C., Rio, RV., Medlock, J., Haines, LR., Nayduch, D. 2008. Infections with immunogenic trypanosomes reduce tsetse reproductive fitness: potential impact of different parasite strains on vector population structure. PLoS Neg Trop Dis. 2: 1-10.

[35] Ibrahim, EAR., Ingram, GA., Molyneux, DH. 1984. Haemagglutinins and parasite agglutinins in heamo lymph and gut of Glossina. Trop Med Parasitol. 6:151-156.

[36] P5;[/Ingram, G.A., Molyneux, D. 1988 Sugar specifities on anti-human ABO (H) blood-group erythrocyte agglutinins (lectins) and haemolytic-activity in the hemolymph and gut extracts of Glossina species. Insect Biochemistry.18: 269-279.

[37] Ingram, G.A., Molyneux, D. 1990. Hemagglutinins in the hemolymph of Glossina fuscipes fuscipes: isolation, partial characterization, selected physico-chemical properties and carbohydrate-binding specificities. Insect Biochemistry. 20:13-27.

[38] Koropatnick, T A., Engle, JT., Apicella, MA. Stabb, EV. Goldman, WE. 2004. Microbialfactor- mediated development in a host-bacterial mutualism. Science. 306: 1186-1188.

[39] Langridge W.P. 1976. A tsetse and trypanosomiasis survey of Ethiopia. London, UK, British. Ministry of Overseas Development. Pp1-97.

Citation: Firew Lejebo, Abebe Girma, "Isolation and Characterization of Midgut Symbiotic Bacteria from Tsetse Flies (G.Pallidipes) and Their Role in Biological Control Methods" International Journal of Research Studies In Biosciences (Ijrsb), Vol. 7, no. 9, pp. 1-11, 2019. http://Dx.Doi.org/10.20431/2349-0365.0709001

Copyright: (C) 2019 Authors. This is an open-access article distributed under the terms of the Creative Commons Attribution License, which permits unrestricted use, distribution, and reproduction in any medium, provided the original author and source are credited. 